\title{
A Guide to Carbonating Beverages at Small Scale ${ }^{1}$
}

\author{
Xuwei Song, Nicholas Wendrick, Charles A. Sims, and Andrew Maclntosh²
}

The objective of this guide is to provide information on how to successfully carbonate beverages on a small scale. Included is information on the benefits of carbonation, common carbonation levels, pros and cons of different carbonation methods, standard procedures to achieve a specific carbonation level, and economic considerations for manufacturers.

\section{Introduction}

\section{Benefits}

Carbonation is an important sensory property for the acceptability of many beverages because it elevates aroma and produces an appealing mouthfeel often described as "tingling" (Dessirier, Simons, O'Mahony, and Carstens 2001). In food products such as soda, sparkling water, tea, juice, or the recently popularized carbonated coffee, carbon dioxide $\left(\mathrm{CO}_{2}\right)$ or a combination of nitrogen and $\mathrm{CO}_{2}$ is typically used to create the bubbles that form and rise through the liquid. Within the wine industry, sparkling wine has become the fastest-growing sector, with a nearly $6 \%$ growth in 2017 and an overall sales increase of 56\% from 2007 to 2017 (Wine Market Council 2017). Overall, the use of carbonation helps to improve and diversify existing beverage options across a wide variety of products.

\section{Carbonation Levels}

Several factors dictate the carbonation level of beverages, including sugar and alcohol; however, the most significant factors are $\mathrm{CO}_{2}$ pressure and temperature. The quantity of
$\mathrm{CO}_{2}$ dissolved in a beverage can impact the flavor, mouthfeel, and palatability of the beverage. The units for measuring the amount of dissolved $\mathrm{CO}_{2}$ are commonly stated as grams of $\mathrm{CO}_{2}$ per liter of beverage $(\mathrm{g} / \mathrm{L})$ or as volumes of $\mathrm{CO}_{2}$ (STP) per volume of liquid ( $\left.\mathrm{vol} / \mathrm{vol}\right)$. The approximate conversion between these two units is $1 \mathrm{vol} / \mathrm{vol}$ being equal to $\sim 2 \mathrm{~g} / \mathrm{L}^{\star}$. The minimum carbonation level for people to detect is $\sim 0.6$ volumes of $\mathrm{CO}_{2}$ (McMahon, Culver, and Ross 2017). Any value lower has a flat perception and is considered noncarbonated. The absolute maximum carbonation level recommended is 8 volumes of $\mathrm{CO}_{2}$. Any higher value will lead to an unappealing bite and excessive burn to the tongue and throat. Also, at higher concentrations of $\mathrm{CO}_{2}$, the bottle becomes a safety hazard due to excessive pressure. For reference, most soft drinks, such as tonic water, are carbonated to 3-3.5 volumes of $\mathrm{CO}_{2}$. To be classified as sparkling wine, the carbonation level must reach a level greater than 2 volumes of $\mathrm{CO}_{2}$ (Bugher 2020). Traditional champagne is carbonated to approximately 4.6 volumes of $\mathrm{CO}_{2}$ but can be found as high as 6 volumes of $\mathrm{CO}_{2}$ (Moriaux et al. 2018). In the beer industry, most craft and lager-style beers are carbonated to 2.4-2.6 volumes of $\mathrm{CO}_{2}$, but this depends on the style. For example, German wheat beer has one of the highest beer carbonation levels at $\sim 5$ volumes of $\mathrm{CO}_{2}$ (Colby 2018). In comparison, British ales have some of the lowest beer carbonation levels at 1.5-2.2 volumes of $\mathrm{CO}_{2}$ (Lauriston n.d.). Additional examples of standard beverage carbonation levels are shown in Table 1 .

${ }^{*}$ The exact conversion is $1 \mathrm{vol} / \mathrm{vol}=1.96 \mathrm{~g} / \mathrm{L}$, which is used for calculations in this guide.

1. This document is FSHN20-34, one of a series of the Food Science and Human Nutrition Department, UF/IFAS Extension. Original publication date October 2020. Visit the EDIS website at https://edis.ifas.ufl.edu for the currently supported version of this publication.

2. Xuwei Song, former undergraduate student; Nicholas Wendrick, undergraduate student; Charles A. Sims, professor; and Andrew Maclntosh, assistant professor, Food Science and Human Nutrition Department, UF/IFAS Extension, Gainesville, FL 32611.

The Institute of Food and Agricultural Sciences (IFAS) is an Equal Opportunity Institution authorized to provide research, educational information and other services

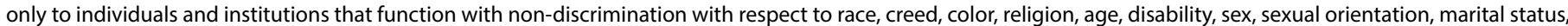

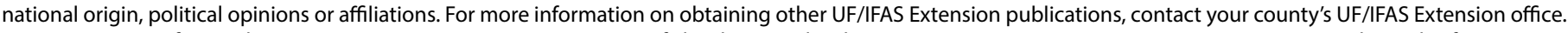
U.S. Department of Agriculture, UF/IFAS Extension Service, University of Florida, IFAS, Florida A \& M University Cooperative Extension Program, and Boards of County Commissioners Cooperating. Nick T. Place, dean for UF/IFAS Extension. 
Table 1. Standard carbonation levels for various carbonated beverages (Lauriston n.d.; Abu-Reidah 2020).

\begin{tabular}{|l|c|}
\hline \multicolumn{1}{|c|}{ Drink Classification } & Volumes of $\mathbf{C O}_{2}$ \\
\hline Champagne & $4.6-6$ \\
\hline German Wheat Beer & 5 \\
\hline High-Carbonated Soda: Coke and Pepsi & $3.5-4$ \\
\hline Mixes: Club Soda \& Tonic Water & $2.5-3.5$ \\
\hline Low-Carbonated Soda: Lemon/Lime & $2.5-3.5$ \\
\hline Typical Lager Beer & $2.4-2.6$ \\
\hline British Ales & $1.5-2.2$ \\
\hline
\end{tabular}

\section{Carbonation Methods: Forced}

\section{Carbonation}

There are two common carbonation methods: the forced carbonation method and the bottled carbonation method, which includes variations such as the traditional champagne method and the Charmat method.

The forced carbonation method is a technique that pumps pressurized $\mathrm{CO}_{2}$ gas into a headspace or liquid inside of a pressurized vessel. Generally in the industry, $\mathrm{CO}_{2}$ is pumped through a porous stone submerged in the beverage, forcing the $\mathrm{CO}_{2}$ to come out as small bubbles that diffuse quickly into the product (Jeandet et al. 2011). The carbonation process is complete once the equilibrium with partial pressure is reached between the product and the headspace. The forced carbonation method is used most commonly in the sparkling beverage industry because it can easily and quickly carbonate large volumes of beverage within hours. The level of carbonation depends mainly on the pressure of $\mathrm{CO}_{2}$ and temperature, because water will have a greater carbon dioxide solubility at lower temperatures (for a given pressure). When the container is opened, the $\mathrm{CO}_{2}$ will escape from the liquid (which will cause the beverage to eventually flatten) as the dissolved $\mathrm{CO}_{2}$ will come to a new equilibrium with the $\mathrm{CO}_{2}$ partial pressure in the atmosphere. While the exact $\mathrm{CO}_{2}$ solubility for beverages will be affected by sugar and ethanol concentrations, an approximation is given in Table 2 .

\section{Procedure: Forced Carbonation}

When conducting the forced carbonation method, a $\mathrm{CO}_{2}$ tank is attached to the pressurized vessel at a constant pressure. By using equations, calculators, or tables, the pressure/ $\mathrm{CO}_{2}$ solubility is determined. The determined pressure is then set to achieve a desired $\mathrm{CO}_{2}$ level. The authors developed an Excel spreadsheet that takes into account multiple parameters of the process and the beverage being carbonated to predict the pressure/temperature required.
This spreadsheet is available upon request. A flowchart for the forced carbonation method is shown in Figure 1.

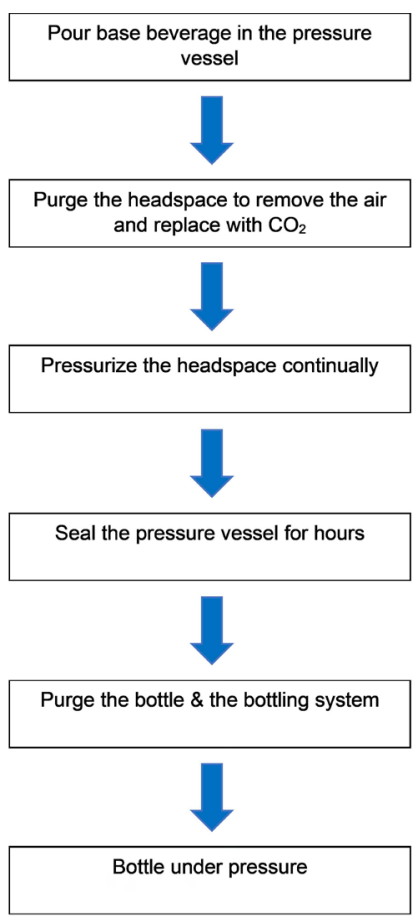

Figure 1. Flowchart for typical procedures for the forced carbonation method.

\section{EXAMPLE}

The step-by-step procedures of the forced carbonation method are listed below, using carbonated water as an example. Assume a company wants to carbonate 6 liters of water to a level of $5 \mathrm{vol} / \mathrm{vol}(9.8 \mathrm{~g} / \mathrm{L})$ within a 6.5 -liter pressurized vessel, such as a serving keg.

1. The water $(6 \mathrm{~L})$ is poured into the pressurized vessel $(6.5$ L).

2. For the desired carbonation level of $5 \mathrm{vol} / \mathrm{vol}$, the initial pressure is set to 39.04 PSIg (3.656 atm absolute) according to the spreadsheet calculation, which takes into account all the parameters, such as standard temperature $\left(5^{\circ} \mathrm{C}=41^{\circ} \mathrm{F}\right)$, ethanol (0 vol/vol), and sugar (0 Brix).

3. Within hours (depending on the temperature and carbonation level), the beverage can be fully carbonated to reach the desired level. Agitation (shaking) can significantly increase the rate of carbonation.

4. The product must be served directly from the carbonated vessel or bottled under pressure, lest the $\mathrm{CO}_{2}$ escape when exposed to the air. 


\section{Economics: Forced Carbonation}

The forced method carbonates the beverage in a pressurized vessel, which is generally made of food-grade stainless steel. As the most common technique used, the forced carbonation method has many advantages, summarized in Table 3. Compared to the traditional method, the forced carbonation method can be completed within a shorter time period. The rate of carbonation is influenced by the temperature and pressure within the pressurized vessel. Additionally, the forced carbonation method requires only a single step, connecting the $\mathrm{CO}_{2}$ tank to the pressurized vessel, which makes this method relatively straightforward to perform, with comparatively low labor costs.

The disadvantages of the forced carbonation method are listed in Table 3. Forced carbonated beverages may cause larger $\mathrm{CO}_{2}$ bubbles within the product (due to other changes within bottled carbonated beverages). Larger bubbles can be associated with subjectively lower qualities in some types of carbonated beverages, such as champagne and wines. Additionally, as mentioned in the previous section, the product must be bottled under pressure, or losses of $\mathrm{CO}_{2}$ will occur.

\section{Carbonation Methods: Bottle Carbonation}

In the wine industry, the bottle carbonation method is often referred to as the champagne, or traditional method. This carbonation method is a labor-intensive and lengthy process, taking anywhere from a few months to several years, depending on the product (Jeandet et al. 2011). To carbonate within the bottle, a secondary fermentation is conducted with specific dosages of yeast and sugar (Jeandet et al. 2011). The yeast will carbonate the beverage by consuming the sugar anaerobically, producing ethanol and $\mathrm{CO}_{2}$ as a byproduct. Over time, the pressure in the bottle builds up as the yeast releases more $\mathrm{CO}_{2}$. The level of carbonation depends on the amount of extra sugar added. As more sugar is added, more alcohol and $\mathrm{CO}_{2}$ will be produced by yeast fermentation. Commercial yeast is widely available as a liquid, as a dry powder, or encapsulated in a gel.

Once mixed with warm water and sugar, the yeast will be activated. Note that each strain of yeast will have different optimal conditions that will yield different properties to the final beverage. As a result of the second fermentation, the product will have a slightly higher alcohol content and secondary flavor notes (from by-products of the fermentation and aging). In sparkling wine production, the yeast is subsequently removed by inverting and turning the bottle to collect settled yeast in the neck over months. The neck of the bottle is then submerged in propylene glycol until the yeast and liquid in the neck of the bottle are frozen. Next, the bottle is opened and the frozen portion removed. The bottle is then refilled with a mixture of the original wine (and occasionally sugar) to be sealed (Jeandet et al. 2011). In brewing operations, the yeast is often left in the bottle to produce a haze when poured into a glass, a practice typical in the production of wheat beers.

An alternate approach to the bottled carbonation method is the Charmat method, in which extra sugar and yeast are added to a larger volume of wine in a pressurized tank until fully carbonated. This process can be completed within weeks but does not yield an identical product to the traditional method. The yeast used in this method is removed via filtration under pressure so that the final product will be clear. Sulfites may be added after either method to inhibit any living yeast residue or bacterial contamination for shelf-stability considerations.

\section{Procedure: Bottle Carbonation}

The procedure to perform the bottle carbonation method is more complicated than the forced carbonation method; it is detailed in Figure 2. The difference between the two methods is that instead of using a $\mathrm{CO}_{2}$ tank to carbonate the product, specific amounts of yeast and sugar are added into the bottle or vessel. Over weeks or months, the final product will be carbonated to the desired level. This method can be efficiently completed at lab, pilot-plant, or commercial scale using the same procedure.

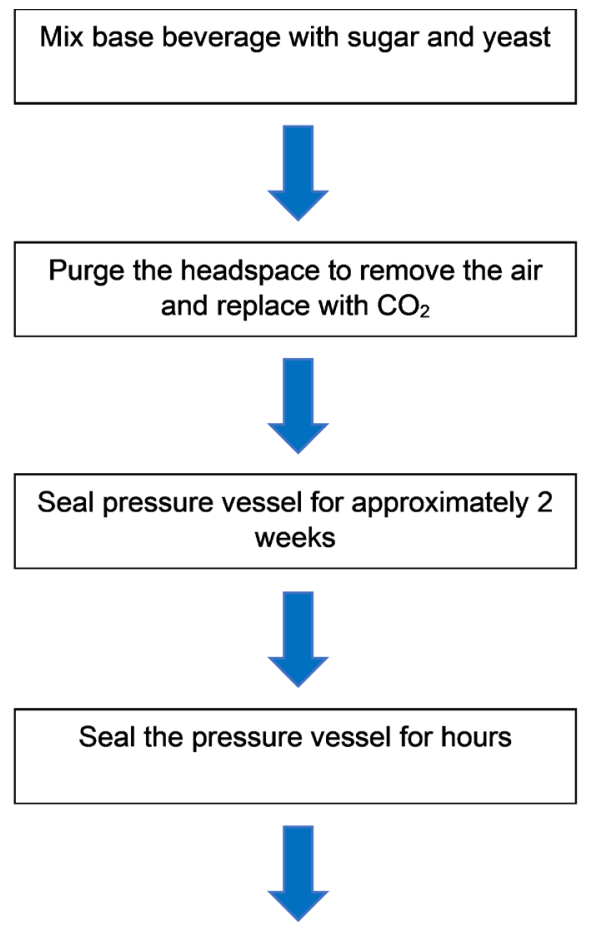

Figure 2. Flowchart for typical procedures of the Charmat carbonation method. 
The step-by-step procedures for the bottle carbonation method are listed below, using carbonated water as an example. Assume a company wants to carbonate 1 liter of water to a level of $5 \mathrm{vol} / \mathrm{vol}(9.8 \mathrm{~g} / \mathrm{L})$ within a 1-liter bottle.

\section{A specific volume of water $(1 \mathrm{~L})$ is poured into the} pressurized vessel $(1 \mathrm{~L})$ with minimal headspace.

2. For a desired concentration of $\mathrm{CO}_{2}(5 \mathrm{vol} / \mathrm{vol}=9.8 \mathrm{~g} / \mathrm{L})$, a ratio between known production of $\mathrm{CO}_{2}$ from glucose is used to calculate the amount of sugar. For every $1 \mathrm{~g}$ sugar, $0.46 \mathrm{~g} \mathrm{CO}_{2}$ and $0.48 \mathrm{~g} \mathrm{ETOH}$ (ethanol) is produced (along with $\sim 0.6$ g yeast). Therefore, to achieve $9.8 \mathrm{~g} / \mathrm{L}$ carbonation, we require $21.3 \mathrm{~g}$ sugar and will get $10.2 \mathrm{~g}$ $\mathrm{ETOH}(\sim 1 \% \mathrm{ETOH}$ by weight). This assumes minimal headspace in the vessel.

3. The carbonation process will end when the yeast consumes all the added sugar, or when the bottle is subjected to conditions that will kill the yeast (e.g., pasteurization). It will generally take several weeks to even years for the yeast to fully consume the sugar, depending on the storage conditions.

4. The yeast can be removed using traditional methods, or can be left in the bottle for consumption, as is the case for some (hazy) beer styles.

\section{Economics: Bottle Carbonation}

Table 4 lists some of the advantages and disadvantages of bottled carbonation. Unique flavor profiles are produced due to the secondary fermentation process. However, failing to remove all the yeast from the bottles can result in variable flavor, as well as turbidity (haze) in the final product. This method can also influence bubble size as the viscosity of the beverage will be affected. Also, operational mistakes can result in a loss of carbonation in the final product, so workers must be trained on carbonation procedures. Moreover, this method has an optimum temperature range of $80^{\circ} \mathrm{F}-100^{\circ} \mathrm{F}$ due to yeast activity, so it cannot be conducted at low temperatures. Appropriately pressure-rated bottles must be used to achieve high carbonation levels. Lastly, any sulfur dioxide or other antifungal agents already present in the beverage will inhibit yeast activity, thus preventing this method from proceeding (Jeandet et al. 2011).

\section{Summary}

The level of carbonation for a beverage is primarily determined by the pressure of $\mathrm{CO}_{2}$ and the temperature. In the forced carbonation process, $\mathrm{CO}_{2}$ is pumped directly into a vessel, forcing a quick increase in pressure. Forced carbonation is the simplest and quickest method with the overall lowest cost compared to the bottle carbonation methods. These factors result in forced carbonation being the most common method used industrially. Bottle carbonation has some advantages over the forced method, including a perceived higher product quality, resulting in the ability to demand a higher price than beverages created using the forced carbonation method. The alcohol content for bottle-carbonated products may be higher due to the secondary fermentation. Ultimately, both methods will accomplish the same goal. The process of carbonation is a value-added step that provides desired characteristics without negative labeling. Historically, the bottle carbonation method has not been widely used by beverage producers because of costs, efficiency, and the level of technical skill required. Modern methods of carbonation allow for a straightforward application at larger volumes for significantly lower cost. Thus, carbonated beverages are becoming increasingly popular, and more beverage makers are using carbonation to diversify their production. The information in this document is supplied to help small-scale beverage producers carbonate their products. With proper equipment and calculations, beverages can be carbonated to exact levels to produce novel products.

\section{References}

Abu-Reidah, I. M. 2020. “Carbonated Beverages.” In Trends in Non-alcoholic Beverages, edited by Charis M. Galanakis. 16-17. London: Academic Press.

Bugher, T. 2020. “TTB: Tax Audit Division: Tax and Fee Rates.” TTBGov. https://www.ttb.gov/tax-audit/ tax-and-fee-rates

Colby, C. 2018. "Brut IPA (V: Carbonation and Packaging)." Accessed October 1, 2019. https://beerandwinejournal. com/brut-ipa-v/

Descoins, C., M. Mathlouthi, M. Le Moual, and J. Hennequin. 2006. "Carbonation Monitoring of Beverage in a Laboratory Scale Unit with On-line Measurement of Dissolved CO2." Food Chemistry 95 (4): 541-553. https:// doi.org/10.1016/j.foodchem.2004.11.031

Dessirier, J.-M., C. T. Simons, M. O. O'Mahony, and E. Carstens. 2001. "The Oral Sensation of Carbonated Water: Cross-Desensitization by Capsaicin and Potentiation by Amiloride." Chemical Senses 26 (6): 639-643. 
Jeandet, P., Y. Vasserot, G. Liger-Belair, and R. Marchal. 2011. "Sparkling Wine Production." Wine Production and Quality, Second Edition. https://doi. org/10.1002/9781118934562.ch 15

Lauriston, R. n.d. "Master the Action: Carbonation." Brew Your Own. http://byo.com/article/ master-the-action-carbonation/

McMahon, K. M., C. Culver, and C. F. Ross. 2017. “The Production and Consumer Perception of Sparkling Wines of Different Carbonation Levels." Journal of Wine Research 28 (2): 1-13.
Moriaux, A.-L., R. Vallon, B. Parvitte, V. Zeninari, G. Liger-Belair, and C. Cilindre. 2018. "Monitoring Gas-Phase $\mathrm{CO} 2$ in the Headspace of Champagne Glasses through Combined Diode Laser Spectrometry and Micro-gas Chromatography Analysis." Food Chemistry 264:255-262. https://doi.org/10.1016/j.foodchem.2018.04.094

Wine Market Council. 2017. "Wine Consumer Segmentation Slide Handbook" Accessed March 2019. http://winemarketcouncil.com/wp-content/uploads/2017/10/2017_ WMC_Wine_Consumer_Segmentation_Slide_Handbook2. pdf

Table 2. Common equilibrium carbonation levels in water at various temperatures*

\begin{tabular}{|c|c|c|c|c|}
\hline $\begin{array}{l}\text { Pressure of Pure } \mathrm{CO}_{2} \\
\text { PSlgauge (Atmosphere } \\
\text { absolute) }\end{array}$ & $\begin{array}{c}\mathrm{CO}_{2 \text { concentration }} \\
\left(\mathrm{Vol} / \mathrm{Vol} \text { at } 0^{\circ} \mathrm{C}\left[32^{\circ} \mathrm{F}\right]\right)\end{array}$ & $\begin{array}{c}\mathrm{CO}_{2 \text { concentration }} \\
\left.\text { (Vol/ } \mathbf{V o l} \text { at } 5^{\circ} \mathrm{C}\left[41^{\circ} \mathrm{F}\right]\right)\end{array}$ & $\begin{array}{c}\mathrm{CO}_{2 \text { concentration }} \\
\left.\text { (Vol/Vol at } 10^{\circ} \mathrm{C}\left[50^{\circ} \mathrm{F}\right]\right)\end{array}$ & $\begin{array}{c}\mathrm{CO}_{2 \text { concentration }} \\
\left.\text { (Vol/Vol at } 15^{\circ} \mathrm{C}\left[59^{\circ} \mathrm{F}\right]\right)\end{array}$ \\
\hline 0 PSIg $(1 \mathrm{~atm})^{* *}$ & 1.60 & 1.37 & 1.17 & 1.01 \\
\hline 5 PSIg (1.34 atm) & 2.15 & 1.83 & 1.57 & 1.36 \\
\hline 10 PSIg (1.68 atm) & 2.69 & 2.30 & 1.97 & 1.70 \\
\hline 15 PSIg (2.02 atm) & 3.24 & 2.76 & 2.37 & 2.05 \\
\hline 20 PSIg (2.36 atm) & 3.78 & 3.23 & 2.77 & 2.39 \\
\hline 25 PSIg (2.70 atm) & 4.32 & 3.69 & 3.17 & 2.74 \\
\hline 30 PSIg (3.04 atm) & 4.87 & 4.16 & 3.57 & 3.08 \\
\hline 35 PSIg (3.38 atm) & 5.41 & 4.62 & 3.97 & 3.43 \\
\hline 40 PSIg (3.72 atm) & 5.96 & 5.09 & 4.37 & 3.77 \\
\hline \multicolumn{5}{|c|}{$\begin{array}{l}\text { *Values calculated using Henry's law assuming beverage properties of water. } \\
\text { ** Note that this chart assumes that at } 0 \text { PSIgauge, there is } 14.7 \text { PSla of pure } \mathrm{CO}_{2} \text { in the headspace; this is usually the case for fermented } \\
\text { beverages at the end of fermentation. }\end{array}$} \\
\hline
\end{tabular}

Table 3. Pros and cons of the forced carbonation method.

\begin{tabular}{|l|l|}
\hline \multicolumn{1}{|c|}{ Pros } & \multicolumn{1}{c|}{ Forced Carbonation Method } \\
\hline Higher carbonation rates (done within hours) & $\begin{array}{l}\text { Requires capital investment (e.g., pressurized vessel, } \mathrm{CO}_{2} \text { tank, } \\
\text { pressure gauge, etc.) }\end{array}$ \\
\hline $\begin{array}{l}\text { Simple to achieve desired carbonation level (less skill required) } \\
\begin{array}{l}\text { Inexpensive (low labor cost, relatively straightforward operation, large } \\
\text { volumes possible) }\end{array}\end{array}$ & \begin{tabular}{l} 
Subjectively lower quality in some beverages (e.g., champagne). \\
\hline
\end{tabular} \\
\hline
\end{tabular}

Table 4. Pros and cons of the bottle carbonation method.

\begin{tabular}{|c|c|}
\hline \multicolumn{2}{|c|}{ Bottle Carbonation Method } \\
\hline Pros & Cons \\
\hline $\begin{array}{l}\text { Perceived higher quality and priced sparkling wine product } \\
\text { lines }\end{array}$ & $\begin{array}{l}\text { Labor intensive (more steps than forced carbonation method, } \\
\text { e.g., yeast removal) }\end{array}$ \\
\hline $\begin{array}{l}\text { Can add flavors to the beverage, such as creamy and toasty } \\
\text { notes, due to yeast activity }\end{array}$ & Requires temperature control \\
\hline Higher alcohol content due to second fermentation & Long maturation period ( 6 months to years) \\
\hline
\end{tabular}

